\title{
The Ontological Argument: A Comparative Look at The Versions of ANSElm AND GHARAWI IsFAHANI
}

\author{
Shiraz Husain Agha \\ Faculty of Philosophy, Al-Mustafa International University, \\ Qom, I. R. Iran
}

\begin{abstract}
There is a hierarchy of arguments for the existence of God. Meaning, they possess many degrees based upon the number of premises and axioms they rest upon. Based upon this general rule, we can divide the existing arguments for the existence of God into three basic categories, starting from the kind of arguments that need the most premises and axioms. In this paper we wish to discuss the ontological argument for the existence of God. In the ontological argument we start from a concept in the mind. In other words, there is no need to accept that there is something real outside the mind. We simply state there is a specific idea in the mind. The beauty of the argument does not only rest upon the fact that there is no need to accept reality, existence or a specific being for the argument to be sound. It seems that the reason why the ontological argument is so named is the use of the term 'existence. We will examine the history of this argument in Western and Muslim circles and compare them with one another. We also wish to defend this argument from the criticisms that have been made against it. Anselm was the first thinker in the West to present the ontological argument as far as history tells us. Sheikh Gharawi Isfahani has presented one version for the ontological argument that is worthy of careful consideration. In this paper we mainly wish to examine the versions of these two thinkers.
\end{abstract}

Keywords: ontological argument, concept, meaning, extension, primary essential predication, secondary common predication 


\section{0. Introduction: The Variety of Arguments for the Existence of God}

There is a hierarchy of arguments for the existence of God. Meaning, they possess many degrees based upon the number of premises and axioms they rest upon. The fewer the number of axioms used in the argument the better that argument will be. This is because the more axioms and premises we use in an argument the more that argument will be susceptible to objection. Of course, the closer the axioms and premises are to being self-evident the better they will be. Thus, the best arguments will be the ones that use fewer premises and axioms and whose premises and axioms are more self-evident.

Based upon this general rule, we can divide the existing arguments for the existence of God into three basic categories, starting from the kind of arguments that need the most premises and axioms. The first kind of argument is the one that starts with the assumption that there is something specific that exists. In other words, this argument states that there is something real. So it accepts reality in general. Then it goes a step further and says that the thing that is real is existence. However, it does not stop there. It then says that there is something specific that exists. For example, it may say that the possible being exists or that motion exists or that the soul exists. Following this, it uses the specific thing that exists to prove the existence of God. Thus, this argument rests upon: 1 . The acceptance of reality. 2. The acceptance of existence. 3. The acceptance of a specific being. Examples of such arguments are the argument by design that attempts to prove God through the existence of design or the argument through motion that proves Him through the specific existence of motion.

The second category of arguments is similar to the first in that it accepts the first of the 3 things just mentioned. However, it does not say that there is necessarily something specific being. It simply says that there is something real and that that reality is manifested in existence. However, it does not say what type of being exists. It then uses this general acceptance of existence to prove God. The prime and famous example of such an argument is the argument of Ibn Sina in his book the al-Isharat wa at-Tanbihat. In this text Ibn Sina argues in the following manner: 1. Something exists. 2. That being is either the Necessary Being or the possible being. 3. In the first case the Necessary Being is proven and in the second case it demands the existence of the Necessary Being (Ibn Sina 1984: III/1-33).

The third category of arguments accepts that there is something real in this world. However, it does not specifically state that the thing that is real is existence. In other words, it gives the possibility that the reality 
may be manifested in non-existence. An example of such an argument is the one presented by Allamah Tabatabai in the footnotes to the $6^{\text {th }}$ volume of the Asfar. There, he presents the following proof for the existence of God: 1. Either something is real or it is not. 2. In the first case we have accepted reality. 3. In the second case, either there is really and actually something real or there is not. 4 . In the first case we have, again, accepted reality since we are saying that there is really nothing real. 5. The second case brings us back to our initial option, i.e. that there is something real. So, we have once again accepted reality. Thus, in any case we have accepted reality. Thus, reality is un-escapable and it is the Necessary Being, i.e. God (Mulla Sadra 1990: VI/15-16).

The third and final category of arguments does not rely upon the acceptance of reality at all. In other words it accepts the possibility that nothing is real and still is able to prove the existence of God. Of course, along with the existence of God, reality, existence and a specific being are proven. However, the acceptance of these things does not form axioms that we must admit in order for the argument to be sound; rather, they are necessary corollaries that result from the conclusion of the argument. This is what occurs in the ontological argument.

\section{0. The Ontological Argument}

In the ontological argument we start from a concept in the mind. In other words, there is no need to accept that there is something real outside the mind. We simply state there is a specific idea in the mind. The beauty of the argument does not only rest upon the fact that there is no need to accept reality, existence or a specific being in order for the argument to be sound, but what is more, since the fact that a concept is in the mind is something known to us intuitively the only axiom used in the argument is something self-evident. It is from here that the argument begins.

\section{1. The Reason Why the Ontological Argument is so Named}

It seems that the reason why the ontological argument is so named is due to the use of the term 'existence' in it as will become clearer further on. This usage is specific to certain versions of the argument that we will examine later on. However, it seems that it is more suitable to name such arguments as 'conceptual' arguments since in them we are not actually using existence per se to prove God; rather, we are using the concept of existence to prove Him. Now, the word 'existence', when used unconditionally, first 
and foremost brings the reality of existence to mind, not the concept of the same. What is more, it is more suitable to name this argument in such a manner that it includes all of the different versions of the argument. Thus, it should be named using an attribute that they all have in common, i.e. the fact that they start from a notion in the mind. Those arguments that begin from the acceptance of the reality of existence are more suitable to be named the 'ontological argument'.

\section{0. A Brief History of the Ontological Argument}

\section{1. The Brief History of the Ontological Argument in Western Circles}

\section{1. 1. Anselm}

Anselm was the first thinker in the West to present the ontological argument as far as history tells us. According to his own account it was revealed to him by God after much supplication and prayer.

\section{1.2. Descartes}

The Cartesian also presented his personal version of the ontological argument using middle terms such as necessity and the likes.

\section{1. 3. Leibnitz}

The philosopher Leibnitz was another western thinker who paid meticulous attention to the ontological argument. What is peculiar to him is that he helped solidify the argument by showing how it depended upon the affirmation of the general possibility of God as an axiom. Leibnitz stated that in order for this demonstration to be sound it must first of all be proven that God is not something impossible. Leibnitz presented an elaborate proof to demonstrate this fact.

\section{1. 4. Kant}

Kant is a philosopher who took a negative approach to the rational approach to proving the existence of God in general and the ontological argument more specifically. Although Kant was a theist and had his own, ethical, approach to establishing God's existence, he was adamant about the fact that reason is able to prove the tenants of metaphysics such as the 
existence of God. In the forthcoming discussions we will take a look at some of Kant's objections to Anselm's argument along with some of the answers that can possibly be given to refute them. It is interesting to note that after Kant's scathing critique we do not see ontological argument come up in western intellectual circles until recent times.

\section{1. 5. Norman Malcolm}

Malcolm is a contemporary thinker who presented a version of the Ontological argument very similar to that of Sheikh Gharawi Isfahani. He is the first thinker after Kant to take serious interest in it and is unique in that he attempts to affirm its validity.

\section{2. The Brief History of the Ontological Argument amongst Muslim Intellectuals}

\section{2. 1. Farabi}

It seems that the first person for whom such a version for the argument for God's existence came to mind was Farabi. The Peripatetic philosopher presented a very concise version of the argument, very similar to the one that was later to be presented by Gharawi Isfahani, in his book al Waridat al Qalbiyyah.. Since Farabi was apt to write in a very concise manner it is possible to interpret the proof as the proof through contingency that was more common at that time. However, the reason why some believe that this argument is an ontological one is the fact that before it, he first mentions the argument through contingency in detail (Fakhry 1986: 5-17).

\section{2. 2. Naraqi}

Following Farabi, the next sage to present the ontological argument was Naraqi in his text Jame al Afkar. This instance of the argument is unique in that Naraqi explains it more in detail.

\section{2. 3. Gharawi Isfahani}

Although primarily a jurisprudent Sheikh Gharawi Isfahani was also interested in philosophical problems as is clear not only from his hair-splitting discussions in the science of usul, but, what is more, in his philosophical poem the Tuhfat al Hakim. In fact, it is in the latter that we find his presentation of the ontological argument that we will relate later on. 


\section{2. 4. Miqdadi Isfahani}

The famous mystic has a collection of epistles, in one of which he has related the ontological argument from one of his contemporaries. This epistle has been related in his biography Neshan az Bineshanha.

\section{0. Saint Anselm's Version of the Ontological Argument}

Anselm's argument is simple enough. It rests upon the following two premises and comes in the form of an exceptive syllogism:

1. (Minor premise): If God did not exist (precedent) He would not be the being greater than which cannot be conceived (antecedent).

2. (Major premise): The antecedent is false.

Conclusion: Therefore, the precedent is also so.

The Proof for the major premise is that God, by definition, is the being greater than which cannot be conceived. This is something that theist and atheist both attest to. It seems that the crux of the demonstration lies in proving the necessity between the precedent and the antecedent, i.e. why is it that if God did not exist He would not be the being greater than which cannot be conceived? Coincidently, it is here that Kant makes his famous objection. Anselm says that this is because the being that exists both inside the mind and also in the external world is greater than the being that simply exists in the mind but lacks entified reality.

\section{1. Gaunilo's Criticism and Its Adduction}

From its inception Anselm's argument was made a target of numerous criticisms. The first one to do so was a monk by the name of Gaunilo. His objection is an attempt to show that if the argument was correct it would lead to the existence of things that we are sure do not exist. Gaunilo stated his objection in the form of an example. He said: I have an idea of a perfect island in my mind. If this idea did not have an instance in the external world it would not be perfect. This goes against the assumption that it is indeed a perfect island.

This criticism can be answered by saying that the idea of a perfect island is self-contradictory. In other words, it is meaningless to say that something is an island, surrounded on all sides by water, limited from all points of view, and 
still call it perfect. Thus, because it is self-contradictory, it cannot exist. However, the idea of God is not so since He is not a possible being by definition.

\section{2. Kant's Criticism and Its Adduction}

Another person that made the argument of Anselm the target of criticism was Kant. He argued by saying that existence is not a perfection for beings; rather, it is simply the locus in which things are true. Thus, if God was only true in the mind and did not exist in the external world it would not subtract from His being the most perfect being (Kant 2007: 501).

This objection seems to go against self-evidentness. It is clear that a being that exists is more perfect that the one that is not. It is interesting to note that Muslim thinkers actually adhered to the idea that existence was perfection; however, they did not argue on its behalf because they considered it self-evident.

\section{0. Sheikh Muhammad Hussain Isfahani's Version of the Ontological Argument}

\section{1. Introduction}

Sheikh Gharawi Isfahani has presented one version for the ontological argument that is worthy of careful consideration. It is interesting to note that a contemporary philosopher named Mackie also presented a very similar version of the argument that Ayatullah Gharawi presented.

Sheikh Gharawi presents this argument in his famous book, the Tuhfat al Hakim. The Tuhfat al Hakim is a philosophical poem (similar to the al-Layali al-Muntazimah of Hakim Sabziwari) that comprises within itself all of the major problems of philosophy. There, in the $12^{\text {th }}$ chapter of this book he states the following:

"The thing that exists, by itself, without any clause, is the Necessary Being, may He be exalted.

And He is, by Himself, a proof for His Self, He is the most truthful of witnesses that can prove Him.

Every sound intellect affirms this, that if there was not something in reality, conforming to the concept of the Necessary Being,

Then this would stem either from the fact that the Necessary Being was impossible, and this goes against His nature,

Or, it stems from His need for a cause, however, under the assumption, He is an instance of that which is Necessary. 
So, a proper look into the nature of necessity, leads to the reality of what was sought out" (Gharawi Isfahani 2011: 235-236).

However, in order to clarify the argument as to protect it from the arguments that many contemporary scholars have leveled against it, it is necessary to first put forward a brief explanation of four terms that we feel are important in the understanding of this argument. We will explain these terms in the form of three important points.

\section{1. 1. The First Point}

We can consider four existences [i.e. for levels of existence] for everything: An external existence, a mental existence, a verbal existence and a written existence.

For example, water possesses a real existence that is its external existence and also has a mental existence that is its mental picture or form. Aside from these two, water also has a verbal existence that is the word that is formed with the letters $\mathrm{w}, \mathrm{a}, \mathrm{t}, \mathrm{e}$ and $\mathrm{r}$, which is usually used when we are speaking. Finally, there is the written existence of water that comes into being after [the word] is written down. Mental existence signifies external existence through an existential indication - or essential indication - that is not conventional [i.e. artificial] in nature. On the other hand, verbal and written existence will indicate external existence if and only if the word in question has been [artificially] coined to denote such a real being.

In order to explain, the mental picture essentially possesses the characteristic of depicting reality. This is so true that this characteristic cannot be taken away from it. Even if the thing that it is depicting does not really exist, the mental picture will still have the distinction of depicting and portraying it. For example, say on a hot summer day the sun is shining directly on the ground [at a distance]. A picture is formed in our mind that indicates to us that there is water on the road [i.e. the phenomenon that is a mirage]. However, after we move forward and reach the place where we thought we saw water we find that there is no water there. Here, even though the mental picture in our minds depicted water in the external world, in reality there was no such water at all. This is a proof that the mental picture essentially possesses the quality of depicting the world outside it - whether this picture has arisen from its real source in the external world (i.e. the real water in our example) or it has been created by other factors in our minds; but it is deceptive in the sense that it depicts something that does not really exist. In any case, this quality of displaying reality is not something that depends upon our intention, conventions and 
our likes and dislikes. It is a distinction that accompanies mental existence, whether we like it or not.

However, the verbal existence (i.e. the spoken word) and the written existence signify external reality because we have concurred that they should do so. No spoken or written word, in and of itself (i.e. essentially), could signify the external reality of water before it we came to a consensus that whenever we hear or see a particular word [for example, 'water'] we should understand from it the real existence of water. It is for this reason that in the Persian language the word 'aab' has been coined to mean water (i.e. the real existence of water) although it is clear that people could have chosen any other word to designate it. In the same way, in other languages other words have been coined to point towards the reality of water.

\section{1.2. The Second Point}

We find ourselves face to face with three terms within the parameters of acquired knowledge: concept, meaning and extension.

'Concept' is the mental existence and is [like] a window by means of which we can see the external world. This window, however, is not wide enough to show us all of reality. Rather, by means of every window [that is a concept] we can see only a portion of reality. In order to see reality in its totality we must open many windows from different angles in its direction and, by using various concepts, we must obtain a complete comprehension of reality.

'Meaning' is the portion of reality that a specific window or concept shows us. For example, consider water that has filled up a swimming pool that is 9 cubic meters large. Assume that this water has also been heated by the sun. Right now, in the external world there exists warm water that is 9 cubic meters large. When we look at this reality by means of the concept 'water' then only one dimension of this reality, that is the dimension of its being water and not, let's say, earth, has been understood by us. On the other hand, its other dimensions such as the fact that it is warm, that it is 9 cubic meters large or other things related to it have still not been comprehended by us [from the viewpoint of this concept in particular]. In order to become familiar with each one of other dimensions of this reality we must utilize new concepts and [open other] windows so that, in the end, we may obtain a more comprehensive knowledge of it.

Finally, 'extension' is the reality that exists in the external world in its entirety and with all dimensions that it possesses; dimensions, each one of which is understood by means of a separate concept. Of course, there may be many aspects of this external reality (i.e. extension) that still have not been 
discovered by human beings. Therefore, even though the extension is only one being, it is the existence of all of the 'meanings' in the external world which various concepts depict for us. What is more, it is the existence of numerous other 'meanings' for which we still have not formed a concept, due to the fact that they have yet to be understood. For example, the warm water [mentioned above] with the volume of 9 cubic meters is an extension which is not more than one thing and, yet, it is the external existence of [numerous] meanings such as: water, warmth and 9 cubic meters; and, as we have previously stated, it is also the existence of many other meanings that are amongst the countless facts that we do not know about water.

Keeping in mind the matters that have just been explained, when we say that the water in the external world is the existence of the concept (i.e. the existence as knowledge) of water we are simply looking at the external existence of water but have not stated anything with regards to the existence of its other dimensions, such as its being warm or being 9 cubic meters. Therefore, only its existence as water is the external existence of the concept of water while its being warm or 9 cubic meters are the external existence of two other concepts; that is to say, the concept of being warm and 9 cubic meters.

\section{1.3. The Third Point}

There are two types of depiction: A man-made (conventional) depiction and a natural (essential) depiction.

The man-made depiction is that in which the depiction of the thing depicting (haki) in relation to the thing that is being depicted (mahki) depends upon a resolution and it is not true that the thing depicting (haki) displays the thing being depicted (mahki) on its own and without the need for a previous resolution. For example, a word that is coined to indicate something does not display the thing it denotes by itself (i.e. essentially) and unless and until there is no resolution at play a given word such as 'water' will not denote the colorless, odorless and tasteless being that exists in nature (i.e. real water). It is instances such as this that the one that has made the resolution [that the given word indicates the given meaning] must [1] first comprehend the thing depicting [i.e. the given word] as well as [2] the reality that is being depicted and [3] following this make the resolution that the word should depict and indicate the thing that has to be depicted.

[However,] natural depiction is that in which the act of depicting (hikayah) of the thing depicting (haki) is essential to it and does not stand in need of any resolution. In this type of depiction, anytime that the thing depicting (haki) comes into existence it will automatically (i.e. essentially) 
show the reality ${ }^{1}$ that it depicts (mahki). In this regard, it does not matter whether that reality has external existence, its existence in the external world is uncertain (in the manner in which physicists have doubted in the external existence of colors) or it does not, fundamentally speaking, exist in the external world. Its external existence may even be impossible. The manner in which concepts depict the realities that they depict is of this nature and, as was previously mentioned, every concept essentially depicts the reality that it depicts. The type of depiction (hikayah) that belongs to concepts is something that can be fathomed through knowledge by presence and everyone can witness such a situation by referring to the concepts that exist in his mind. In this way, mental concepts can even depict impossible things or those that do not exist and show them [to the mind]. This is so even though these types of things do not, fundamentally speaking, exist in the external world. They neither possess a material and sensible existence nor an immaterial and non-sensible one. Even though this is true, the ideas of such things exist in our minds, such as the concept of the combination of contradictories, the concept of a vicious circle and the concept of an infinite regress, none of which can exist in the external world. Based upon the essential distinction of every concept, these concepts depict the things they depict [i.e. their instances in the external world]. Therefore, at least those concepts that depict impossible things are formed within our mind without the need of any [previous] relation with their instances [in the external world], instances we are not capable of forming a relation with given the fact that they basically do not exist (see: Fayyadhi 2007: 155-157).

\section{2. The Main Body of the Ontological Argument of Sheikh Gharawi Isfahani}

This brief introduction having been presented let us now turn to the argument of Ayatullah Gharawi itself. The argument, in brief, comes in the form of an exceptive syllogism the antecedent of which is a disjunctive conditional proposition:

1. (Minor premise) If the Necessary Being did not exist (precedent), then it would either be a possible being or an impossible being (antecedent).

1 Here, 'reality' is not tantamount to existence. Rather, the reality of everything is harmonious with that thing: [So,] the reality of existence is its existence and the reality of non-existence or something that is impossible is its' [real] non-existence. Technically speaking, the reality of everything is in line with that thing itself. 
2. (Major premise) However, both options in the antecedent are impossible.

3. (Conclusion) Therefore, the precedent is also wrong; thus, the Necessary Being exists.

The necessity between the precedent and the antecedent rests upon the idea that the division between of things into possible, impossible and necessary things is a division in which there is not another option at play. This is because, in essence, this is two divisions, in each of which the two categories are contradictions of one another. In other words, we say: Either existence is impossible for something or it is not. If it is not, then either existence is necessary for it or it is not. What is more, if there were really something that was neither one of the three things just mentioned then it would lead to the combination or negation of contradictory concepts, i.e. existence and non-existence. This is because the only other fathomable option at play is that both existence and non-existence are necessary for something or that both of them are impossible for them.

The proof for the major premise rests upon the idea that in any division the categories that are obtained as a result are opposed to one another. This is because the categories are, in reality, the thing being divided in addition to a specific clause. Each one of the categories possesses their own specific clause and thus it is impossible for one thing to be an instance of more than one category.

\section{3. An Elaborate Explanation of the Argument of Sheikh Gharawi Isfahani}

Having become acquainted with the argument in brief let us, keeping in mind the introduction that we first mentioned, explain this proof in detail.

Both sides in this debate, i.e. both the theist and the atheist, have a conception of God in his mind. If this was not true then it would be impossible for the atheist to negate or doubt in Him. This is because affirmation and judgment is secondary to conception and until we do not understand something it is impossible for us to pass a judgment about it.

This concept, i.e. the concept of the Necessary Being, possesses the quality of depicting its meaning, like every other concept. This is because the act of depicting is something that is essential to concepts in the mind.

There are also two other concepts in the mind, i.e. that of existence and non-existence. These concepts also depict their respective meanings in an essential manner. 
Now, the question arises: With which one of the latter two meanings does the meaning of the Necessary being unite? In other words, is the meaning of the Necessary Being present in an instance where the meaning of existence is present or is it present in an instance where the meaning of non-existence is present?

It is impossible for the latter to be true. This is because there is a necessary relationship between the meaning of non-existence and that of either one of the two meanings of impossibility or possibility. In other words, if the meaning of the Necessary Being was present in the same instance that non-existence was present then either the meaning of impossibility would also be present in that instance or the meaning of possibility.

However, based upon the idea that the division into possibility, impossibility and necessity is one that does not allow the meanings of the categories obtained to combine in one instance, we can conclude that it is impossible for the meaning of necessity to combine with that of possibility or impossibility.

Thus, if must negate the idea that the meaning of the Necessary Being is present in the same instance where the meaning of non-existence is present. If this is so, then it is necessary that the meaning of the Necessary Being be present in the instance where the meaning of existence is present. This means that the Necessary Being exists.

\section{4. A Look at the Objection of Ayatullah Jawadi Amuli}

Ayatullah Jawadi Amuli has commented upon the arguments of both Sheikh Gharawi Isfahani as well as that of St. Anselm. However, he considers both of them flawed with the same problem. This is confusion between the concept of the God and His instance in the external world.

In brief, this sage asks: What is meant by the term 'existence' in this argument? Is the concept of existence implied? If this is so then the only conclusion that this argument can derive is that the concept of existence is affirmed for the concept of God. This does not, however, prove the external existence of God, i.e. the fact that He possesses the instance of existence. However, if what is meant is the instance of existence then although the argument will aim at proving the fact that God exists in the external world it will not be able to do so. This is because God's not possessing external existence does not lead to the concept of the Necessary Being to be that of the impossible or possible being. In other words, this argument rests upon the idea that these three concepts are opposed to one another and aims at showing how, if God did not exist in the external world, it would lead to them combining together. However, in the view of the objector, there is no necessary relation between God's being the instance of a possible or impossible being and His Essence to be one of the two which is the very antecedent of the minor premise. 
"The critical fallacy of Anselm's argument arises from his failure to differentiate between the notion of existence and extension. The notions of maximal perfection, existence and necessity, which are included in the notion of God, regardless of having or lacking external extensions, have their respective meanings. In other words, the notions of maximal perfection, existence, and necessity - regardless of being true by predication as extension and being instantiated, or being invalid by the same predication and not being instantiated - do carry their essences and essential parts by predication as essence, because predication as essence is concerned with concept, and predication as extension reflects whether a concept has any external extension. By paying attention to the difference between the notion of existence and its extension, that is existence by predication as essence and existence by predication as extension, Anselm's fallacy becomes evident. The concept of 'that than which nothing greater can be conceived' is contradicted, and therefore, absurdity is invited, only if existence is negated from this concept by predication as essence. However, God's non-existence in the external world, that is, His lack of existence by predication as extension, does not entail negation of perfection from Him by predication as essence. Therefore, it has to be established what Anselm means by existence when he says, 'If that than which nothing greater can be conceived, can be conceived not to exist, it is not that than which nothing greater can be conceived. If he means existence by predication as essence, it is a valid assertion. Since, the negation of existence form the concept of God, the most superlative perceivable perfection, is contradictory. This, however, does not prove such a concept us instantiated in reality. Nonetheless, if Anselm means existence by predication as extension, that is existence in reality, then there is no mutual necessity between the negation of existence from God by predication as extension and negation of existence from His concept by predication as essence. Thus, while the concept of the most superlative perceivable perfection carries all of the concepts, which are included within it, and therefore, no contradiction is implied, it may not have any external extension. On this basis, the ontological argument does not indicate that to hold the complement of its desired conclusion is reducible to absurdity. If the concept of the most adequate perfection lacks a real extension, it is not contradictory, since contradictory propositions must have an identical manner of predication [...]" (Jawadi Amuli 1999: 161-163).

The objector then goes on to make a similar objection to some of the proofs of the mystic presented to corroborate the unity of existence (wahdat al-wujud) (ibid.: 164-167). 


\section{5. A Critique of the Objection of Jawadi Amuli}

It seems that objector has confused two different meanings of one term, i.e. predication as essence and predication as extension. If truth be told, in this argument we wish to affirm existence, perfection or necessity for the meaning of the Necessary Being, in other words, the Necessary Being as predication as extension not the concept of the Necessary Being, i.e. the Necessary Being as predication by essence. To explain, sometimes these two terms are used to condition propositions and at other times they are used to condition the parts of those, in other words simple things. In the former case, predication as essence implies that the predicate and the subject of the proposition are one in essence while predication as extension implies that they are not one in essence by rather in reality. However, when these two terms are used to condition simple things, not propositions, then they imply the concept of the thing they are conditioning and its meaning. The famous sage Muhammad Ridha al Muzaffar explains this in his famous textbook on logic, al Mantiq:

"When you affirm something for something else then sometimes your view is limited to the concept itself, in the sense that it is what is intended in this affirmation; such as when you say: 'Man is a rational animal'. In this case man is called: 'man, through primary essential predication'. Sometimes, however, your view in the affirmation moves past the concept, going even further away [from your mind] in the sense that you view the concept in order to make it something that depicts its meaning and a indicator of the latter; such as when you say: 'Man laughs' or 'Man is at loss' so you point to the specific individuals through the concept and they are what are intended in the judgment. The observation of the concept in the judgment and placing it as the subject of the judgment is simply a means through which we pass a judgment on the individuals [...]" (al-Muzaffar 1988: 82-83).

Thus, although we begin the ontological argument from the concept of God, this is simply meant to be a bridge to its meaning and it is the meaning of God that is the axis around which the argument revolves. The argument asks whether existence can be negated from this meaning or not. The negation of existence from this meaning would imply a contradiction in the meaning itself. However, we do not have any access to the meaning of things. All we have at our disposal is their concepts. Nevertheless, concepts display their respective meanings essentially and it is impossible that there is no unity between the two. As we stated in the introduction to this argument, 
the indication of the concept with respect to its meaning is essential. Thus, it would be impossible for a concept to depict something that its meaning did not have but which we artificially placed in opposition to. This is not the case with words. We can coin a word to refer to some concept and meaning and following this coin it for something else. Thus, its indication is something artificial. However, we could not force a concept to depict something and thereafter make it depict something else. No matter what we do the concept would still depict the first thing that it was indicating. This is because its act of depiction is something essential to it. Thus, if the concept of God is depicting existence, perfection and necessity in the meaning of God then this is not something man-made or artificial rather it stems from the fact that these things actually are there in the meaning itself.

\section{6. The Unity of the Mind and the Objective World:}

\section{A Solution to Criticisms?}

In the hopes of finding a solution to the problem of the confusion between concept and extension in the ontological argument some sages have taken refuge in a philosophical principle that has been demonstrated in the Transcendent Wisdom. That principle is the unity of the mind and the external world. In order to explain, in Sadrian philosophy the adherents of this school of thought have stated that when a human being understands a universal concept or makes a universal affirmation then, in reality, this is not an instance of acquired, husuli, knowledge; rather, it is the knowledge by presence of certain immaterial beings albeit from a spiritual 'distance. For example, when one understands the concept 'man' in reality one is intuitively witnessing the Perfect Man who possesses all perfections that a human could have. However, being in the material world and, more specifically, attached to the body, causes this presential knowledge to be weak. Thus, we see the immaterial man from a distance. We therefore assume that this 'man' could be predicated of a number of human beings. This resembles someone who sees someone from a distance. Although he is in reality seeing a specific individual since many of his particular qualities cannot be seen properly he says that it is possible for him to be any of a number of people.

Keeping in mind this general philosophical principle it is possible to state that the person who understands the universal notion of 'a Necessary Being' has in fact come into contact with a specific individual of this notion. Thus, based upon this principle the notion of God would be a valid and sound proof for the existence of an instance of this notion in the external world (see: Jawadi Amuli 1999: 176-177). 


\section{0. A Comparison of the Versions of the Ontological Argument}

Both versions of the ontological argument presented above seem infallible from the objections that were leveled against them. However, it seems that the version that takes as its starting point the necessity of God as opposed to His perfection is much more philosophically solid. This is because God's perfection is something that stems from His being a necessary being, i.e. a being that must exist in all and every situation. Because this is so $\mathrm{He}$ must be perfect; otherwise, if He lacked some perfection or quality then His existence would be possible with that perfection or quality. This is something that has been discussed by Muslim philosophers under the title 'the Essentially Necessary Being is Necessary from all Points of View' (Tabatabai 2001: 55). Thus, if we begin the ontological argument from God's Necessity there would be one fewer premise to prove and it would protect our demonstration from criticism at least to one more degree.

Received: May $23^{\text {rd }}, 2015$

Accepted: September $29^{\text {th }}, 2015$

\section{References}

Fakhri, Majid (1986), “The Ontological Argument in the Arabic Tradition: The Case of al-Fārābi”, Studia Islamica 16 (64): 5-17.

Fayyadhi, Ghulam Ridha (2007), Daramadi bar Marefatshenasi-ye Eslami [An Introduction to Islamic Epistemology], Qum, Mu'assasat Imam Khomayni.

Gharawi Isfahani, Muhammad Husain (2011), Tuhfat al Hakim, Qum, Entesharat-e Bustan-e Ketab.

Ibn Sina (1984), al-Isharat wa at-Tanbihat, Qum, Daftar-e Nashr-e Ketab, $2^{\text {nd }}$ edition. Jawadi Amuli, Abdullah (1999), Tabyin-e Barahin-e Ethbat-e Khoda [A Commentary on Theistic Arguments], Qum, Isra, $3^{\text {rd }}$ edition.

Kant, Immanuel (2007), Critique of Pure Reason, translated by Norman Kemp Smith, New York, Palgrave Macmillan, $2^{\text {nd }}$ edition.

al-Muzaffar, Muhammad Ridha (1988), al-Mantiq [Logic], Qum, Ismailiyan Publications, $4^{\text {th }}$ edition.

Mulla Sadra, Sadr al-Din Muhammad Shirazi (1990), al-Hikmat al Muta'aliyah $f i$ al-Asfar al-Arba'a al-Aqliyyah [The Transcendent Wisdom in the Four Intellectual Journeys], Beirut, Daru Ihya al-Turath al-Arabi.

Tabatabai, Muhammad Husain (2001), Nihayat al-hikma, Qum, Mu'assasat annashr al-islami. 